\title{
Validation of the Arabic version of the Perinatal Anxiety Screening Scale (PASS) among antenatal and postnatal women
}

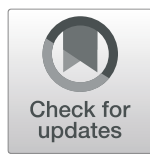

Hoda Jradi ${ }^{1,2^{*}}$, Thikrayat Alfarhan ${ }^{2}$ and Anas Alsuraimi ${ }^{3}$

\begin{abstract}
Background: Anxiety among women in the perinatal period is common. Assessing the severity of perinatal anxiety will help monitor the progress of the patient through the stages of anxiety and facilitated the treatment. This study assesses the validity and reliability of the "Perinatal Anxiety Screening Scale" (PASS) in the Arabic language.

Methods: The PASS was translated into Arabic. Two hundred seventeen women in the antenatal and postnatal phase participated (92 antenatal and 125 postnatal) answered to PASS, GHQ12, EPDS-10, and DASS-21. Content validity, factor analysis, internal consistency, and test retest reliability were assessed.

Results: Content Validity Index (CVI) and Content Validity Ratio (CVR) were .88 and 0.79; respectively. The scale loaded on four components: acute anxiety, social anxiety, and dissociation; specific fears and trauma; general anxiety and adjustment; and perfectionism and control. Cronbach's Alpha value for the scale was 0.78 and test retest correlation coefficient was 0.94 . PASS significantly correlated with EPDS-10 (rho=0.46), GHQ-12(rho=0.58), the three components of DASS-21 (0.47, 0.50, and 0.43; respectively), and experiencing adverse life events.

Conclusion: The Arabic translated version of the PASS showed reasonably adequate validity and reliability and can be used to screen for anxiety disorder among women in the perinatal phase.
\end{abstract}

Keywords: Anxiety, PASS, Pregnancy, Perinatal, Antenatal, postnatal, Arabic, Saudi Arabia

\section{Background}

Maternal health can be negatively impacted by untreated anxiety $[1-3]$. Anxiety can also negatively affect the behavioral development, emotional and cognitive status of the child [4], and the mother-infant relationship [5, 6]. For this reason, the detection of problematic anxiety via the use of an effective screening tool may be important in screening for risk of problematic anxiety, prevention, early intervention, and treatment in the field of perinatal mental health.

\footnotetext{
* Correspondence: Hoda.Jradi@gmail.com

${ }^{1}$ King Abdullah International Medical Research Center, Ministry of National Guard Health Affairs, Riyadh, Saudi Arabia

${ }^{2}$ College of Public Health and Health Informatics, King Saud Bin Abdulaziz University for Health Sciences, Mail code 2350, 11426 Riyadh, Saudi Arabia Full list of author information is available at the end of the article
}

Knowing the severity of anxiety is important to guide the treatment for the patient [6]. Also, continuous monitoring of response to psychological and/or pharmacological treatment is essential to evaluate the effectiveness of the plan of care [7]. Depending on the severity of their symptoms, women can be assigned to maternity and childcare services, counseling services, psychosocial therapy, or to psychiatric hospitalization in severe cases [6].

A validated tool that assesses the severity of perinatal and postnatal anxiety will help monitor the progress of the patient through the stages of anxiety and facilitated the adjustment of the treatment approach as required $[8,9]$.

There are no available scales in the Arabic language to assess antenatal anxiety and classify patients according to the stages of severity of symptoms. The Depression,

(c) The Author(s). 2020 Open Access This article is licensed under a Creative Commons Attribution 4.0 International License, which permits use, sharing, adaptation, distribution and reproduction in any medium or format, as long as you give appropriate credit to the original author(s) and the source, provide a link to the Creative Commons licence, and indicate if changes were made. The images or other third party material in this article are included in the article's Creative Commons licence, unless indicated otherwise in a credit line to the material. If material is not included in the article's Creative Commons licence and your intended use is not permitted by statutory regulation or exceeds the permitted use, you will need to obtain permission directly from the copyright holder. To view a copy of this licence, visit http://creativecommons.org/licenses/by/4.0/. The Creative Commons Public Domain Dedication waiver (http://creativecommons.org/publicdomain/zero/1.0/) applies to the data made available in this article, unless otherwise stated in a credit line to the data. 
Anxiety and Stress Scale (DASS-21) [10] have been validated in Arabic and is used among the general population. However, this scale measures are limited in classifying the severity of anxiety in the perinatal period because it has not been validated in perinatal samples and failed to include measures of anxiety related to pregnancy [11]. The Edinburgh Postnatal Depression Scale (EPDS [12] has also been validated in Arabic and is a self-administered scales that screens for depression and classifies women at risk for anxiety if they score over a pre-established cut-off score ; however, the scale does not classify the severity of anxiety according to pre-established severity ranges. The EPDS is lacking in psychometric sensitivity for screening for anxiety disorders $[12,13]$.

The Perinatal Anxiety Screening Scale (PASS) is a 31item self-administered scale to screen for anxiety in antenatal and postnatal women that was developed and validated among a sample of pregnant women in 2014[14]. The scale includes measures such as fear of birth or fear that harm will come to the baby. It has a four-factor structure that assesses symptoms of acute anxiety, worry and fear, perfectionism, control and trauma, and social anxiety [14]. The validity and reliability study of the original scale reported a good internal consistency for the four dimensions of the scale (coefficient alpha of $0.90,0.89,0.86$, and 0.87 ; respectively) and a test re-test correlation coefficient of 0.74 [14]. The correlation between the PASS and other measures of depression and anxiety ranged between 0.77 and 0.83 . A cut-off score of 26 was established to identify $68 \%$ of women at risk of an anxiety disorder, severe anxiety as 42 to 93 , mild to moderate anxiety as $21-41$, and minimal anxiety as 0 to $20[14,15]$. Additionally, the Turkish version of the scale (PASS-TR), showed high sensitivity and specificity for a self-report scale, a cut-off value of 16 , a high total internal consistency (coefficient alpha of 0.95), and correlated positively with other existing valid and reliable measures of anxiety [16].

The main aim of this study is to validate the Perinatal Anxiety Scale (PASS) in the Arabic language to increase its usefulness as a screening tool for identifying and tracking problematic antenatal and postnatal anxiety.

\section{Methods}

\section{Participants recruitment and data collection}

This study was used a cross-sectional methodological design. A sample of 217 perinatal (92 in antenatal phase and 125 in postnatal phase) were enrolled in the validity and reliability study of the Arabic version of the PASS scale (7 participants :1survey item). Sample size was judged sufficient according to the recommendations of a minimum subject to item ratio of at least 5:1 [17]. Women were recruited randomly as they entered the clinics from the obstetrics/gynecology and pediatric clinics at King Fahad National Guard Hospital in Riyadh. The chosen clinics provide care for women and their infants from different socioeconomic backgrounds. The clinic serves personnel from the military, their families, in addition to employees affiliated with the hospital and a large university system and their dependents. Surveys were collected anonymously and it took approximately 15 minutes for completion. Illiterate women and those with a disability that prevents them from participating in the study were excluded. Written consent was obtained from all participants. Data collection continued for a period of three months.

\section{Translation and validation process}

The validation process started with the standard "forward-backward" procedure [18] by translating the original version of the PASS questionnaire from English into classical Arabic by two independent professional translators and subsequently back translated into English by Two other independent translators and checked for consistency. Content validity of the translated Arabic version was assessed by presenting the translated instrument to a group of experts (an obstetrics/gynecology physician, two psychologists, and two nurses and a health educator from the maternity clinic). The group evaluated the relevance and cultural appropriateness of each item of the scale. Content Validity Ratio (CVR) and Content Validity Index (CVI) were generated. the Arabic version and the English version of the tool were administered consecutively within 15 min to a group 15 bilingual female office employee. Correlation of the English and Arabic version was calculated using the Spearman correlation coefficient (rho). Finally, the translated Arabic version of the PASS questionnaire was piloted in a sample of new mothers $(N=20)$ to ensure clarity of all terms. Additionally, the convergent validity of the PASS was assessed by concurrently administering the Arabic versions of the Edinburgh Postpartum Depression Scale (EPDS-10) and the General Health Questionnaire (GHQ-12) and the Depression, anxiety, and Stress Scale 21 (DASS-21) to study participants. Both the EPDS-10 and the GHQ-12 are valid and reliable scales in the Arabic language previously used to screen for risk of depression and risk of psychological distress in the prenatal and postpartum period $[19,20]$. The DASS-21 is also a valid and reliable scale in the Arabic language that consists of 21 items measuring depression, anxiety, and stress with higher scores indicating higher level of psychological distress in all three domains [21].

Participants were also asked to complete a demographic questionnaire (age, gender, marital status, employment status, level of education, and income), and questions related to adverse life events experienced 
within the last year (divorce in the family, problems at work or university, death in the family, illness in the family, financial problems, other personal problems, or health problems related to pregnancy or delivery). We anticipated that a positive correlation between these negative life events and the PASS will add to the validity of the scale.

\section{Statistical analysis}

Responses were collected anonymously and once the data collection process was completed, data were imported from the excel sheets into Stata (version 14.0, College Station, TX: StataCorp LLC), for analysis purposes. All scales in this study were scored according to recommendations, and means and standard deviations were calculated for each scale. Composite variables were generated based on the final scores as high, moderate, or low to indicate levels of psychological distress among participants for all scales. Study variables were summarized, in aggregate, using standard descriptive statistics and frequencies of responses were reported. Content validity Ratio and Content Validity Index were calculated for content validity check. Factor structure of the questionnaire was performed using principal component analysis (PCA) with Varimax rotation. The reliability of the scale was checked via internal consistency and test retest reliability. Cronbach's alpha coefficient was reported for internal consistency (alpha $\geq 0.70$ was considered acceptable) ([22]. Test-retest reliability was conducted $(N=30)$ within one week interval and a correlation coefficient was obtained.

\section{Results}

\section{Participants' characteristics}

Overall, 283 women were recruited for this study. Twenty of them were consented for the initial piloting phase, 30 of them for the test re-test reliability, 16 withdrew before completing the survey and were not included in the final sample size; the remaining sample of 217 women were included in the final sample size for this study.

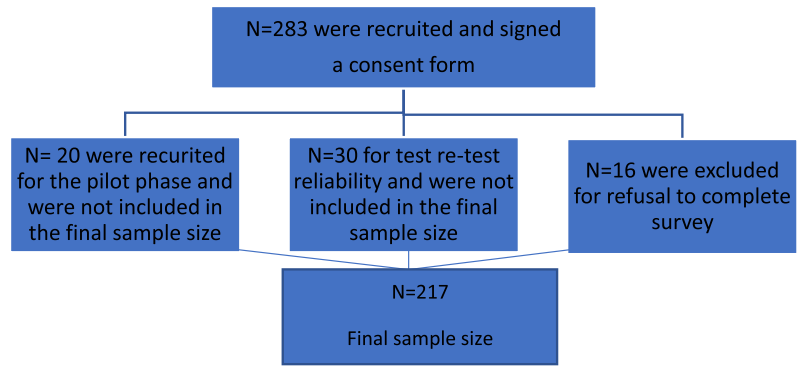

The mean age of participants was 28.89 years (range between 19 and 44) with a standard deviation of 7.07 years. Most of the sample (70.51\%) reported having a college degree. The majority $(58.06 \%)$ did not work and $56.28 \%$ reported that their income was adequate for their lifestyle; an income of less than 10,000 Saudi Riyals (SAR) was reported by approximately half $(47.69 \%)$ of the sample. Using the suggested cut-off values for the English version of the PASS scale [14] of 0-20 (risk of minimal anxiety), 21-41 (risk of moderate anxiety), and above 41 (risk of severe anxiety), 34.10\% of the participating women reported a risk of moderate anxiety and $47.0 \%$ reported a risk of severe anxiety. Participants' characteristics are presented in Table 1.

Frequency of responses to each of the questions of the Arabic version of the PASS scale are displayed in Table 2. The mean average score for the Arabic version of the PASS scale was $41.01(\mathrm{SD}=20.55)$ (range: 0 to 93$)$. The mean EPDS-10 score was $17.57(\mathrm{SD}=4.32)$ (range: from 0 to 30 ) with $82.40 \%$ of the surveyed women scoring above 13 for depression symptoms (indicative of risk of depression) [12]. Additionally, the mean score for GHQ12 was $10.81(\mathrm{SD}=7.30)$ (range: 0 to 36$)$ and $36.87 \%$ of participants exhibited an above 12 score (indicative of risk mental disorder and risk of psychological distress) [23]. The mean scores for the three components of the DASS-21 were 11.04 $(\mathrm{SD}=9.70)$ for depression, 11.73 $(\mathrm{SD}=9.46)$ for anxiety, and $17.10(\mathrm{SD}=10.26)$ for stress

Table 1 Characteristics of study participants $(N=217)$

\begin{tabular}{|c|c|c|}
\hline Characteristics & $\mathbf{N}$ & $\%$ \\
\hline \multicolumn{3}{|l|}{ Age $(\mu=28.89 \pm 7.07)$} \\
\hline $18-25$ & 51 & 23.50 \\
\hline $26-34$ & 126 & 58.06 \\
\hline$\geq 35$ & 40 & 18.30 \\
\hline \multicolumn{3}{|l|}{ Marital Status } \\
\hline Married & 214 & 98.62 \\
\hline Divorced/Separated/Widowed & 3 & 1.38 \\
\hline \multicolumn{3}{|l|}{ Level of Education } \\
\hline Highschool or less & 64 & 29.49 \\
\hline College or more & 153 & 70.51 \\
\hline \multicolumn{3}{|l|}{ Employment Status } \\
\hline Unemployed & 127 & 58.52 \\
\hline Employed/Student & 90 & 41.47 \\
\hline \multicolumn{3}{|l|}{ Income (SR) ${ }^{a}$} \\
\hline$<10,000$ & 104 & 47.46 \\
\hline$\geq 10,000$ & 113 & 52.07 \\
\hline \multicolumn{3}{|l|}{ Pregnancy Stage } \\
\hline Antenatal & 92 & 42.40 \\
\hline Postnatal & 125 & 5760 \\
\hline \multicolumn{3}{|l|}{ Level of Anxiety (PASS) } \\
\hline Low & 41 & 18.89 \\
\hline Moderate & 74 & 34.10 \\
\hline High & 102 & 47.0 \\
\hline
\end{tabular}

${ }^{a}$ SRSaudi Riyals 
Table 2 Participants' response to the Arabic version of the PASS scale ( $N=217$ )

\begin{tabular}{|c|c|c|c|c|}
\hline PASS Items & $\begin{array}{l}\text { Not at all } \\
\mathrm{N}(\%)\end{array}$ & $\begin{array}{l}\text { Sometimes } \\
\mathrm{N}(\%)\end{array}$ & $\begin{array}{l}\text { Often } \\
\mathrm{N}(\%)\end{array}$ & $\begin{array}{l}\text { Almost Always } \\
\text { N (\%) }\end{array}$ \\
\hline \multicolumn{5}{|l|}{ Total anxiety score $(\mu=41.02 ; S D=20.55)$} \\
\hline 1.Worry about baby/pregnancy & $69(31.80)$ & $79(36.41)$ & $46(21.20)$ & $23(10.63)$ \\
\hline 2.Fear that harm will come to the baby & $78(35.94)$ & $78(35.94)$ & $40(18.43)$ & $21(9.68)$ \\
\hline 3.A sense of dread that something will come to the baby & $56(25.81)$ & $65(29.91)$ & $32(14.75)$ & $64(29.49)$ \\
\hline 4.Worry about many things & $55(25.35)$ & $88(40.55)$ & $41(18.89)$ & $33(15.21)$ \\
\hline 5.Worry about the future & $56(25.81)$ & $62(28.57)$ & $27(12.44)$ & $72(33.18)$ \\
\hline 6.Feeling overwhelmed & $35(15.67)$ & $5(23.50)$ & $33(15.21)$ & $99(45.62)$ \\
\hline 7.Really strong fears about things (needles, blood, birth, pain) & $45(20.74)$ & $72(33.18)$ & $53(24.2)$ & $47(21.66)$ \\
\hline 8.Sudden rush of extreme fear or discomfort & $30(13.82)$ & $59(27.19)$ & $46(21.20)$ & $82(37.79)$ \\
\hline 9. Repetitive thoughts that are difficult to stop or control & $44(20.28)$ & $70(32.26)$ & $38(17.51)$ & $65(29.95)$ \\
\hline 10.Difficulty sleeping even when I have the chance to sleep & $33(15.21)$ & $72(33.18)$ & $42(19.35)$ & $70(32.26)$ \\
\hline 11. Having to do things in a certain way or order & $35(16.93)$ & $78(35.94)$ & $52(23.96)$ & $52(23.96)$ \\
\hline 12.Wanting things to be perfect & $68(31.34)$ & $53(24.24)$ & $51(23.50)$ & $45(20.74)$ \\
\hline 13.Needing to be in control of things & $57(26.27)$ & 65 (29.95) & $50(23.04)$ & $45(20.74)$ \\
\hline 14.Difficulty stopping checking things over and over & $42(19.35)$ & $73(33.64)$ & $36(16.39)$ & $66(30.41)$ \\
\hline 15.Feeling jumpy or easily startled & 33 15.21) & $58(26.73)$ & $42(19.35)$ & $84(38.71)$ \\
\hline 16.Concerns about repeated thoughts & $39(17.97)$ & $77(35.48)$ & $38(17.51)$ & $63(29.0)$ \\
\hline 17. Being on guard or needing to do watch out for things & $60(27.65)$ & $89(41.01)$ & $32(14.75)$ & $36(16.59)$ \\
\hline 18.Upset about repeated memories, dreams, or nightmares & $40(18.43)$ & $61(28.11)$ & $30(13.82)$ & $86(39.63)$ \\
\hline 19.Worry that I will embarrass myself in front of others & $34(15.67)$ & $58(26.73)$ & $34(15.67)$ & $91(41.94)$ \\
\hline 20.Fear that others will judge me negatively & $36(16.59)$ & $58(26.73)$ & $28(12.90)$ & $95(43.78)$ \\
\hline 21.Feeling really uneasy in crowds & $31(14.29)$ & $46(21.20)$ & $29(13.36)$ & $111(51.15)$ \\
\hline 22.Avoiding social activities because I might be nervous & $26(11.98)$ & 43(19.82) & $27(12.44)$ & $121(55.76)$ \\
\hline 23. Avoiding things which concern me & $53(24.24)$ & $59(27.19)$ & $44(20.28)$ & $61(28.11)$ \\
\hline 24.Feeling detached like watching yourself in a movie & $28(12.90)$ & $32(14.75)$ & $14(6.45)$ & $143(65.90)$ \\
\hline 25.Loosing track of time and can't remember what happened & $31(14.29)$ & $54(24.88)$ & $25(11.52)$ & $107(49.31)$ \\
\hline 26.Difficulty adjusting for recent changes & $34(15.67)$ & $49(22.58)$ & $33(15.21)$ & $101(46.54)$ \\
\hline 27.Anxiety getting in the way of being able to do things & $32(14.75)$ & $79(36.41)$ & $37(17.05)$ & $69(31.80)$ \\
\hline 28.Racing thoughts making it hard to concentrate & $33(15.21)$ & $68(1.34)$ & $43(19.82)$ & $73(33.64)$ \\
\hline 29.Fear of losing control & $36(16.59)$ & $59(27.19)$ & $34(15.67)$ & $88(40.55)$ \\
\hline 30.Feeling panicky & $26(11.98)$ & $45(20.74)$ & $26(11.98)$ & $120(55.30)$ \\
\hline 31.Feeling agitated & $25(11.52)$ & $37(17.05)$ & 27 (12.44) & $128(58.99)$ \\
\hline
\end{tabular}

symptoms. Almost $37 \%$ of the participants reported a risk of severe and extremely severe anxiety according to the DASS-21. Mean scores for the four scales and the composite score for adverse life events are presented in Table 3.

\section{Reliability of the instrument}

Internal consistency using Cronbach's alpha coefficient as a measure of reliability of the Arabic version of the PASS questionnaire was found to be 0.94 for the whole sample indicating very satisfactory results. It was 0.83 , $0.80,0.86$, and 0.90 for the four sections of the scale.
The results of the test-retest reliability of the Arabic version of the PASS tool showed to be acceptable with a correlation coefficient of 0.78 .

\section{Validity of the instrument}

Validity of the instrument was assessed using convergent validity. The correlations between the Arabic version of PASS, the Arabic version of the EPDS-10, the Arabic version of the GHQ-12, the three components of the DASS-21 (Depression, Anxiety, and Stress), and the score of the stressful life events within the last 12 months were significantly positive (Spearman's rho $=$ 
Table 3 Distributions of scales (medians, means, and standard deviations) and correlations with PASS

\begin{tabular}{lllll}
\hline Scale & Median & Mean (SD) & Range & Spearman's Rho $(\boldsymbol{p}$-value $)$ \\
\hline PASS & 39 & $41.02(20.55)$ & $3-97$ & - \\
EPDS-10 & 18 & $17.57(4.32)$ & $5-26$ & $0.46(<0.001)$ \\
GHQ-12 & 9 & $10.8(7.30)$ & $0-33$ & $0.58(<0.001)$ \\
DASS-21 (depression) & 8 & $11.04(9.70)$ & $0-42$ & $0.47(<0.001)$ \\
DASS-21 (anxiety) & 10 & $11.73(9.46)$ & $0-40$ & $0.50(<0.001)$ \\
DASS-21 (stress) & 16 & $17.10(10.26)$ & $0-42$ & $0.43(<0.001)$ \\
Adverse life events (total) & 6 & $6.7(5.4)$ & $0-19$ & $0.28(0.003)$ \\
Divorce & 0 & $0.54(108)$ & $0-4$ & $0.11(0.10)$ \\
Problems at work & 0 & $0.64(0.97)$ & $0-3$ & $0.2(0.002)$ \\
Death in the family & 0 & $0.96(1.31)$ & $0-3$ & $0.06(0.42)$ \\
IIIness in the family & 0 & $0.97(1.27)$ & $0-3$ & $0.16(0.02)$ \\
Money problems & 1 & $1.16(1.11)$ & $0-3$ & $0.18(0.007)$ \\
Personal problems & 1 & $1.11(1.12)$ & $0-3$ & $0.23(0.0005)$ \\
Pregnancy problems & 1 & $1.32(1.17)$ & $0=3$ & $0.12(0.07)$ \\
\hline
\end{tabular}

$0.46 ; p<0.001$, Spearman's rho $=0.58 ; p<0.001$, Spearman's rho $=0.47 ; p<0.00$ ' Spearman's rho $=0.50 ; p<$ 0001, spearman's rh $=0.43 ; p<0.001$, and Spearman's rho $=0.28 ; p=0.003$; respectively), indicating that those who had perinatal anxiety showed higher levels of depression and higher levels of psychological disorders. Particularly those who reported experiencing problems at work, illness in the family, money problems, and personal problems significantly correlated with the PASS scores (Table 3).

Results of the content validity results from the expert panel displayed a mean Content Validity Ratio (CVR) of 0.79 and a mean Content Validity Index (CVI) of 0.88 .

\section{Factor structure}

In order to confirm the structure of the Arabic version of the instrument and demonstrate its construct validity and similarity to the English version, the Principal Component Method for factor analysis with varimax rotation was applied using the original four factor structure of the instrument. The four factors jointly accounted for $54.53 \%$ of the total detected variance. Factor 1 (acute anxiety, social anxiety, and dissociation) accounts for $37.12 \%$ of the total variance, Factor 2 (specific fears and trauma) $7.51 \%$, Factor 3 (general anxiety and adjustment) $5.20 \%$, and factor 4 (perfectionism and control) $4.11 \%$. Results for factor structure of the scale are presented in Table 4.

\section{Discussion}

This is the first study conducted to evaluate the validity and reliability of the Arabic Perinatal Anxiety Scale. This study showed that the Arabic version of the PASS is valid and reliable for use in the Arabic speaking populations and have good psychometric properties. Women who participated in this validation study were in the antenatal and postnatal phase, reflecting the suitability of the scale for both phases. Also, participants were from different age groups and different socioeconomic status.

The reliability coefficient was assessed and the Arabic version of PASS, similarly to the original English version of the scale (0.95) [14] and the Turkish version of the scale (0.96) [16], demonstrated high reliability (0.94). The test retest reliability of 0.78 was acceptable and comparable to the test retest reliability of the original scale of 0.74 [14].

The factor analysis was conducted with retaining the four components structure of the original version of the scale. Similarly, to the original English version [14] and the Turkish version [16] of the PASS, the questions loaded on the four factors; however, the actual distribution of the questions for the Arabic version of the PASS varied across the four components. The original scale factor structure were "acute anxiety and adjustment" for factor 1 (constructs related to panic disorder, dissociative disorder, and adjustment difficulties), "general worry and specific fear" for factor 2 (constructs related general anxiety disorder and phobia), "perfectionism, control and trauma" for factor 3 (constructs related to obsessive compulsive disorder and posttraumatic stress disorder), and "social anxiety" for factor 4 (constructs related to social anxiety) [14]. For the Arabic PASS, factor 1 included acute anxiety, social anxiety, and dissociation; factor 2 included specific fears and trauma; factor 3 included general anxiety and adjustments; and factor 4 included perfectionism and control. Actually, these results of factor analysis are similar to those obtained for the 
Table 4 Results of factor analysis: factor structure and factor loadings

\begin{tabular}{ll}
\hline PASS Items & Factor \\
\hline Factor 1: Acute anxiety, Social Anxiety, and Dissociation & 0.55 \\
8.Sudden rush of extreme fear or discomfort & 0.64 \\
15.Feeling jumpy or easily startled & 0.64 \\
19.Worry that I will embarrass myself in front of others & 0.55 \\
20.Fear that others will judge me negatively & 0.73 \\
21.Feeling really uneasy in crowds & 0.65 \\
22.Avoiding social activities because I might be nervous & 0.70 \\
24.Feeling detached like watching yourself in a movie & 0.59 \\
25.Loosing track of time and can't remember what happened & 0.70 \\
23. Avoiding things which concern me & 0.51 \\
28.Racing thoughts making it hard to concentrate & 0.62 \\
29.Fear of losing control & 0.78 \\
30.Feeling panicky & 0.82 \\
31.Feeling agitated &
\end{tabular}

Factor 2: Specific Fears, and trauma

$\begin{array}{ll}\text { 1.Worry about baby/pregnancy } & 0.59 \\ \text { 2.Fear that harm will come to the baby } & 0.72 \\ \text { 3.A sense of dread that something will come to the baby } & 0.62 \\ \text { 4.Worry about many things } & 0.68 \\ \text { 5.Worry about the future } & 0.40 \\ \text { 7.Really strong fears about things (needles, blood, birth, pain) } & 0.44 \\ \text { 9.Repetitive thoughts that are difficult to stop or control } & 0.54 \\ \text { 10.Difficulty sleeping even when I have the chance to sleep } & 0.53 \\ \text { 16.Concerns about repeated thoughts } & 0.52 \\ \text { 18.Upset about repeated memories, dreams, or nightmares } & 0.49\end{array}$

\section{Factor 3: General Anxiety and Adjustment}

6.Feeling overwhelmed

17. Being on guard or needing to watch out for things

0.62

26.Difficulty adjusting for recent changes

0.72

27.Anxiety getting in the way of being able to do things

\section{Factor 4: Perfectionism and Control}

11. Having to do things in a certain way or order

12.Wanting things to be perfect

13.Needing to be control of things

14.Difficulty stopping checking things over and over

Variance (\%) (total: 54.53\%)

37.12

7.51

Turkish version of the scale on factor 4 (perfectionism and control) and partially for the other three factors [16]. These changes in the structure of components distribution for the scale may reflect the cultural and linguistic adaptation of the scale to the Arabic speaking population.

As hypothesized, the Arabic PASS had positive significant associations with previously validated Arabic versions of the EPDS-10, GHQ-12, and DASS-21. It is not surprising that the PASS correlated positively with the EPDS since anxiety and depression are known to occur concurrently in more than $50 \%$ of the time [24]. Results are indicative that some of the women in this group may suffer from anxiety with or without depression. The PASS can identify anxiety status regardless of the depression status among women in the antenatal and postnatal stage. Further studies are recommended for assessing the ability of the PASS to distinguish between 
those who have anxiety only or in combination with other psychological disorders among pregnant and postpartum women. There was also a positive, significant, but weaker, association between the PASS and the adverse life events. This existing low magnitude association may be due to the way people cope with adverse life events [25]. For example, persons with good coping strategies may score low on the Arabic PASS even though their score for adverse life events is high. It is highly recommended to conduct further investigation regarding experienced life events and anxiety and the impact of coping strategies.

The PASS scale is composed of 31 items which is considered too long for a screening test; particularly in the clinical setting. However, it is useful for researchers in all settings because of its capacity of detecting anxiety disorders at higher rates than other scales and including broad constructs of anxiety disorder not present in other scales. Levels of anxiety (47\%) detected by the Arabic version of the scale among this sample were not far from the values detected by the Turkish version (50\%) for their recruited samples [16]. The mean scores reported for the Turkish version seem to be lower because they used a modified scoring techniques and different cut-off value from the original scale to adapt it to cultural differences in responding [16]. The Arabic version of the PASS was validated against the EPDS-10, GHQ-12, DASS-21, and constructs associated with adverse life events and not against a standard diagnostic instrument or criteria use in the clinical setting, making it of limited use in the clinical setting and with no recommendations for a cut-off values that can be used for diagnostic purpose. Further validation work on establishing clinical cut off scores and severity ranges for the PASS in Arabic populations is needed.

This study has some limitations. Participants were recruited from clinics in the Eastern part of Riyadh and the sample cannot be considered representative of the entire population of Riyadh or the Saudi population. However, formal Arabic was used to translate and validate the tool, making it comprehensible and useful for all Arabic speaking nations.

\section{Conclusions}

This study provides the literature with an Arabic scale for assessing anxiety during the antenatal and postnatal period. The Arabic version of the PASS showed to be valid and reliable and can be used as a screening tool for anxiety among the Arabic speaking population.

\section{Abbreviations}

PASS: Perinatal Anxiety Screening Scale; EPDS: Edinburgh Postnatal Depression Scale; DASS: Depression, Anxiety, and Stress Scale; GHQ: General Health Questionnaire; CVR: Content Validity Ratio; CVI: Content Validity Index; SAR: Saudi Riyals

\section{Acknowledgements}

We would like to thank the hospital administrators that facilitated data collection

\section{Authors' contributions}

HJ designed the study, analysed the data, wrote the first draft. TA collected the data and interpreted findings. $\mathrm{HJ}$ and TA reviewed and edited the final draft. AS coded and entered data and conducted further analysis. All authors have read and approved the manuscript.

\section{Funding}

King Abdullah International Medical Research Centre Provided funding for data collection expenses.

Availability of data and materials

The datasets analysed during the study are available from the corresponding author on reasonable request and after approval of the concerned

authorities in the organization.

Ethics approval and consent to participate

This research was approved by the Institutional Review Board at king Abdullah international Medical Research Centre. All participants signed a consent form prior to enrolment in the study.

Consent for publication

Not applicable.

\section{Competing interests}

The authors declare that they have no competing interests.

\section{Author details}

'King Abdullah International Medical Research Center, Ministry of National Guard Health Affairs, Riyadh, Saudi Arabia. ${ }^{2}$ College of Public Health and Health Informatics, King Saud Bin Abdulaziz University for Health Sciences, Mail code 2350, 11426 Riyadh, Saudi Arabia. ${ }^{3}$ College of Medicine, Alfaisal University, Riyadh, Saudi Arabia.

Received: 17 April 2020 Accepted: 22 November 2020

Published online: 04 December 2020

\section{References}

1. Johnson R, Slade P. Obstetric complications and anxiety during pregnancy: is there a relationship? J Psychosom Obstet Gynecol. 2003;24(1):1-14.

2. Matthey S, Barnett B, Howie P, Kavanagh DJ. Diagnosing postpartum depression in mothers and fathers: whatever happened to anxiety? J Affect Disord. 2003;74(2):139-47.

3. Milgrom J, Gemmill AW, Bilszta JL, Hayes B, Barnett B, Brooks J, Ericksen J, Ellwood D, Buist A. Antenatal risk factors for postnatal depression: a large prospective study. J Affect Disord. 2008;108(1-2):147-57.

4. Bergman K, Sarkar P, Glover V, O'Connor TG. Maternal prenatal cortisol and infant cognitive development: Moderation by infant-mother attachment. Biol Psychiatry. 2010;67(11):1026-32

5. Stevenson-Hinde J, Shouldice A, Chicot R. Maternal anxiety, behavioral inhibition, and attachment. Attach Hum Dev. 2011;13(3):199-215.

6. Austin M, Highet N: the Guidelines Expert Advisory Committee: Clinical practice guidelines for depression and related disorders-anxiety, bipolar disorder and puerperal psychosis-in the perinatal period. A guideline for primary care health professionals. A guideline for primary care professionals Beyond Blue-The National Depression Initiative, Melbourne 2011.

7. NffHaC E. Antenatal and postnatal mental health: clinical management and service guidance. London: National Institute for Health and Care Excellence; 2014.

8. Ronk FR, Korman JR, Hooke GR, Page AC. Assessing clinical significance of treatment outcomes using the DASS-21. Psychol Assess. 2013;25(4):1103.

9. Tingey R, Lambert M, Burlingame G, Hansen N. Assessing clinical significance: Proposed extensions to method. Psychother Res. 1996;6(2):109-23.

10. Lovibond PF, Lovibond SH. The structure of negative emotional states: Comparison of the Depression Anxiety Stress Scales (DASS) with the Beck Depression and Anxiety Inventories. Behav Res Ther. 1995;33(3):335-43.

11. Swallow BL, Lindow S, Masson E, Hay D. The use of the General Health Questionnaire (GHQ-28) to estimate prevalence of psychiatric disorder in early pregnancy. Psychol Health Med. 2003;8(2):213-7. 
12. Cox JL, Holden JM, Sagovsky R. Detection of postnatal depression: development of the 10-item Edinburgh Postnatal Depression Scale. Br J Psychiatry. 1987;150(6):782-6.

13. Muzik M, Klier C, Rosenblum K, Holzinger A, Umek W, Katschnig H. Are commonly used self-report inventories suitable for screening postpartum depression and anxiety disorders? Acta Psychiatr Scand. 2000;102(1):71-3.

14. Somerville S, Dedman K, Hagan R, Oxnam E, Wettinger M, Byrne S, Coo S, Doherty D, Page AC. The perinatal anxiety screening scale: development and preliminary validation. Arch Women Ment Health. 2014;17(5):443-54.

15. Somerville S, Byrne SL, Dedman K, Hagan R, Coo S, Oxnam E, Doherty D, Cunningham N, Page AC. Detecting the severity of perinatal anxiety with the Perinatal Anxiety Screening Scale (PASS). J Affect Disord. 2015; 186:18-25.

16. Yazııı E, Mutu Pek T, Uslu Yuvacı H, Köse E, Cevrioglu S, Yazııı AB, Çilli AS, Erol A, Aydin N. Perinatal Anxiety Screening Scale validiy and reliability study in Turkish (PASS-TR validity and reliability). Psychiatry Clin Psychopharmacol. 2019;29(4):609-17.

17. Osborne JW, Costello AB. Sample size and subject to item ratio in principal components analysis. Pract Assess Res Eval. 2004;9(1):11.

18. McKenna SP, Doward LC. The translation and cultural adaptation of patientreported outcome measures. Value Health. 2005;8(2):89-91.

19. Lee DT, Yip AS, Chiu HF, Leung TY, Chung TK. Screening for postnatal depression: are specific instruments mandatory? J Affect Disord. 2001;63(13):233-8.

20. Navarro P, Ascaso C, Garcia-Esteve L, Aguado J, Torres A, Martín-Santos R. Postnatal psychiatric morbidity: a validation study of the GHQ-12 and the EPDS as screening tools. Gen Hosp Psychiatry. 2007;29(1):1-7.

21. Ali AM, Ahmed A, Sharaf A, Kawakami N, Abdeldayem SM, Green J. The Arabic version of the depression anxiety stress Scale-21: cumulative scaling and discriminant-validation testing. Asian J Psychiatry. 2017;30:56-8.

22. Cortina JM. What is coefficient alpha? An examination of theory and applications. J Appl Psychol. 1993;78(1):98.

23. Goldberg D: Manual of the general health questionnaire: Nfer Nelson; 1978.

24. Spinhoven P, van Balkom A, Nolen WA. Comorbidity patterns of anxiety and depressive disorders in a large cohort study: the Netherlands Study of Depression and Anxiety (NESDA). J Clin Psychiatry. 2011;72(3):341-8.

25. Headey B, Wearing A. Coping with the social environment: The relationship between life events, coping strategies and psychological distress. Community Health Stud. 1988;12(4):444-52.

\section{Publisher's Note}

Springer Nature remains neutral with regard to jurisdictional claims in published maps and institutional affiliations.

Ready to submit your research? Choose BMC and benefit from:

- fast, convenient online submission

- thorough peer review by experienced researchers in your field

- rapid publication on acceptance

- support for research data, including large and complex data types

- gold Open Access which fosters wider collaboration and increased citations

- maximum visibility for your research: over $100 \mathrm{M}$ website views per year

At $\mathrm{BMC}$, research is always in progress.

Learn more biomedcentral.com/submissions 